\title{
Os impactos da crise hídrica sobre a população do município de Campinas/SP $(2012-2016)^{1}$
}

The impacts of the water crisis on the population of Campinas/SP (2012-2016)

Julia Lopes da Silva[a] (D), Patricia Rodrigues Samora[a,b]

[a] Pontifícia Universidade Católica de Campinas (PUC-Campinas), Programa de Pós-graduação em Arquitetura e Urbanismo, Campinas, SP, Brasil

[b] Universidade de São Paulo (USP), Faculdade de Arquitetura e Urbanismo da USP (FAU), Campinas, SP, Brasil

Como citar: Silva, J. L., \& Samora, P. R. (2019). Os impactos da crise hídrica sobre a população do município de Campinas/SP (2012-2016). urbe. Revista Brasileira de Gestão Urbana, 11, e20180210. https://doi.org/10.1590/21753369.011.e20170210

\section{Resumo}

A recente crise hídrica vivenciada no Sudeste brasileiro pode ser considerada uma "crise anunciada", fruto, principalmente, do gerenciamento inadequado dos recursos hídricos e da ocupação indevida das áreas produtoras de água. 0 período de seca resultou em extensas consequências que afetaram tanto os ecossistemas naturais quanto os moradores da região, os quais se viram privados desse recurso essencial. Nesse contexto, este artigo se propõe a analisar, por meio de revisão teórico-conceitual, levantamento documental e pesquisa de campo, os impactos da seca sobre os moradores das bacias hidrográficas do Ribeirão Anhumas e do Rio Capivari (áreas que apresentam diferenças de qualidade de vida e de infraestrutura bastante discrepantes entre si), situadas no município de Campinas/SP, bem como suas vivências e percepções em relação a esse evento de seca. Com isso, objetiva-se evidenciar os efeitos da injustiça ambiental observada no município, a extrema relevância de espaços participativos e a necessidade de transparência e prestação de contas por parte dos órgãos gestores.

Palavras-chave: Gestão urbana. Crise hídrica. Justiça ambiental.

\section{Abstract}

The recent water crisis in southeastern Brazil can be considered an "announced crisis", mainly due to inadequate management of water resources and undue occupation of water producing areas. The drought has had far-reaching consequences, which have affected both the natural ecosystems and the residents of the region, which were deprived of this essential resource. In this context, and, through a theoreticalconceptual review, this article proposes to analyze a documentary survey and field research, the impacts of drought on the residents of the Ribeirão Anhumas and Capivari river basins (areas that show differences of quality of life and infrastructure that are quite different from each other), located in the city of

${ }^{1}$ Editor responsável pelo processo de avaliação deste artigo: Harry Bollmann. 
Campinas/SP, as well as their experiences and perceptions regarding the lack of water. With this, it aims to show the effects of environmental injustice in the municipality, as well as the extreme relevance of participatory spaces and the need for transparency and accountability by the managing bodies.

Keywords: Urban management. Water crisis. Environmental justice.

\section{Introdução}

De acordo com o Intergovernmental Panel on Climate Change (IPCC, 2014), a temperatura média da atmosfera vem aumentando constantemente ao longo das últimas décadas, o que gera grande preocupação em função dos extensos impactos socioambientais causados pelo aquecimento global (IPCC, 2014). Diversas consequências desse processo já foram observadas, tais como o derretimento dos polos, o aumento do nível do mar e a incidência de desastres naturais. Somado a isso, são vivenciados também extremos climáticos, como ondas de calor, invernos excepcionalmente rigorosos, enchentes, secas, furacões etc., nas mais diversas cidades do mundo, os quais acarretam consequências diretas aos ecossistemas naturais e ao bem-estar da população (Marengo et al., 2015).

A atual crise ambiental pode ser caracterizada como um problema de ordem não apenas ambiental, mas também social; portanto, é fruto de uma série de relações sociopolíticas (como políticas públicas, acordos internacionais, disputas geopolíticas etc.) que devem ser consideradas nessa discussão. Um exemplo que merece destaque é a dificuldade de acesso à moradia digna por grande parte da população em função da lógica capitalista que opera nas cidades, o que causa diversas alterações dinâmicas e estruturais aos centros urbanos e aos ecossistemas naturais. Em função disso, inúmeras consequências são observadas em todo o país, como ocupação de áreas ambientalmente sensíveis, desmatamento, poluição, enchentes, periferização etc., que estão interligadas e atingem tanto o meio ambiente quanto a sociedade. Constata-se, portanto, a necessidade de integração de ações mais adequadas e menos destrutivas, de forma a garantir a manutenção das cidades e dos ecossistemas.

Chama-se atenção aqui para a crise hídrica estadual - período em que foram registrados baixos volumes hídricos em rios de todo o Sudeste brasileiro, afetando seriamente o abastecimento de inúmeros municípios - que agravou ainda mais o precário cenário ambiental local. Pode-se dizer que essa foi uma "crise anunciada", fruto, principalmente, da combinação de baixos índices pluviométricos, gerenciamento inadequado dos recursos hídricos e ocupação irregular das áreas produtoras de água. Além disso, destaca-se também o crescimento da população brasileira ao longo das últimas décadas (IBGE, 2010), condição que, combinada ao fato de que o verão de 2014 registrou a temperatura máxima mais alta dos últimos 50 anos (Reis, 2014), implicou uma extrema seca vivenciada, já que havia grande número de pessoas consumindo um recurso que estava disponível em menor quantidade.

Tendo em vista essa e outras crises de caráter urbano-ambiental, torna-se essencial repensar o sistema de desenvolvimento atual, o qual, além de excludente e segregador, faz dos pobres suas principais vítimas. Direitos básicos, tais como o direito à água, à moradia, à alimentação, à educação, entre outros, devem ser atendidos, conforme preveem os diversos tratados internacionais dos quais o Brasil é signatário. Para isso, portanto, o enfoque do planejamento urbano não pode se dar de forma autônoma, mas sim subordinado ao conhecimento intrínseco da realidade global, como defende Santos (2005). Assim, uma visão holística se faz necessária para a gestão socioambiental dos centros urbanos, e, portanto, pensar a gestão ambiental se torna imprescindível para uma gestão urbana satisfatória, tanto em escala local como global.

De acordo com Coriolano et al. (2013), observa-se no Brasil um incentivo à implantação de políticas públicas que visam reverter as desigualdades socioterritoriais. Contudo, os instrumentos de planejamento territorial ainda se submetem aos interesses do capital imobiliário, o que dificulta a concretização desse objetivo. Ainda segundo os autores, isso se dá, principalmente, pela pressão provocada no poder público para o atendimento de interesses privados, mascarada pela disseminação do discurso da promoção do "desenvolvimento econômico", diante da falta de apropriação dos 
instrumentos democráticos pela sociedade civil organizada. Consequentemente, prevalece a lógica da produção capitalista (Coriolano et al., 2013).

No que diz respeito à região Sudeste, área em que o município de Campinas, objeto de estudo deste artigo, localiza-se, há registros de que secas sazonais intensas já a atingiram em 1953, 1971, 2001 e, mais recentemente, em 2014. Nesse contexto, o objetivo deste artigo é discorrer acerca da injustiça ambiental à luz dos resultados obtidos na pesquisa de Silva (2017), que verificou, por meio da aplicação de questionários em pesquisa de campo, a forma como o período de crise hídrica foi administrado pela municipalidade e como isso afetou a população residente na cidade. A partir disso, constatou-se a injustiça ambiental a que parte da população da cidade foi submetida, bem como a falta de transparência com que são tratadas questões acerca da gestão ambiental municipal e o quão preocupantes elas são.

\section{Material e método}

O enfoque deste artigo se dá nas consequências do período de seca sentidas por parte da população de Campinas/SP. Para tanto, trabalhou-se com levantamentos de campo e bibliográfico, que visam à obtenção de dados a respeito da vivência da população no período de seca, bem como a construção teórica da problemática urbano ambiental como instrumento para leitura dos resultados obtidos em campo.

Escolheu-se como unidade de avaliação a bacia hidrográfica, já que ela possui todos os elementos para integração de processos biogeofísicos, econômicos e sociais, além de ser a unidade natural que permite integração institucional e articulação da pesquisa com o gerenciamento dos recursos hídricos (Tundisi, 2008). Foram selecionadas duas bacias hidrográficas municipais para realização da pesquisa de campo: a sub-bacia do Ribeirão Anhumas e a sub-bacia do Rio Capivari, que apresentam maiores densidades populacionais, com 2.476 hab. $/ \mathrm{km}^{2}$ e $3.776 \mathrm{hab} . / \mathrm{km}^{2}$, respectivamente. 0 critério para escolha dessas bacias, além da densidade, deu-se em função do Índice de Desenvolvimento Humano Municipal (IDHM), elaborado a partir de componentes relacionados à longevidade, à educação e à renda.

Enquanto a sub-bacia do Ribeirão Anhumas apresenta unidades de desenvolvimento humano (UDHs) com os maiores IDHMs, a bacia do Rio Capivari apresenta UDHs com os menores IDHMs (PNUD et al., 2015), o que é evidenciado pela Figura 1, que sobrepõe as localidades das UDHs no mapa hidrológico de Campinas. Os pontos amarelos representam as UDHs com maiores IDHMs, e os pontos vermelhos, as UDHs com menores IDHM.

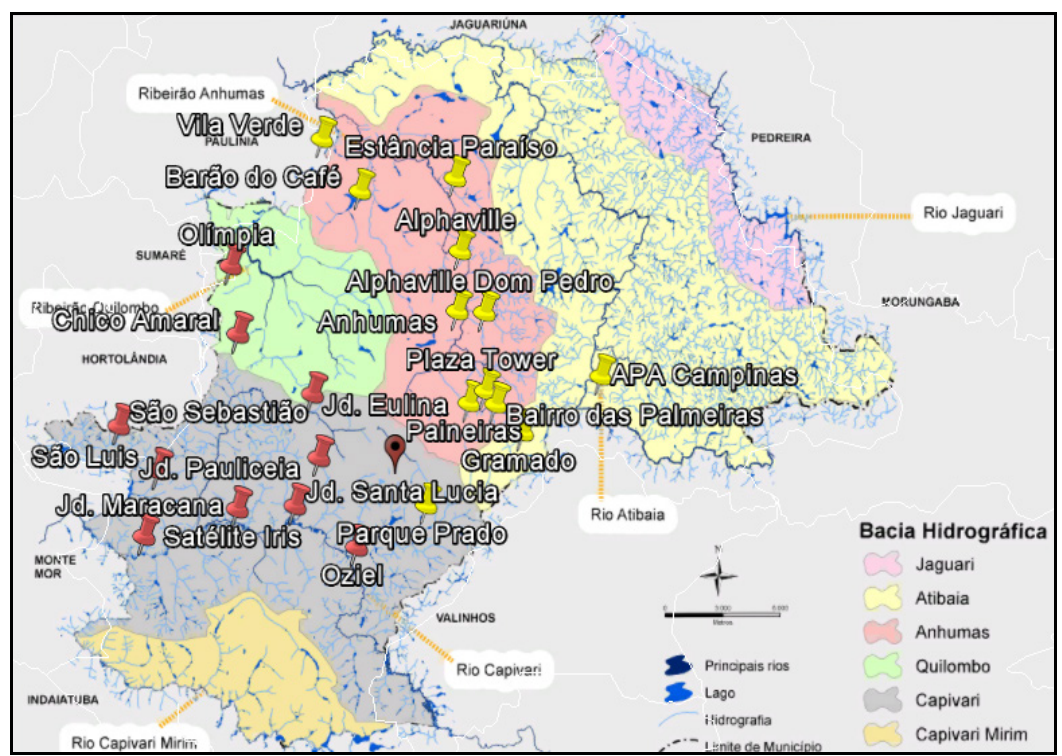

Figura 1 - Mapa hidrográfico de Campinas e localização das UDHs com melhores e piores IDHMs. Fonte: elaborada pela autora com base na Secretaria Municipal do Verde, do Meio Ambiente e do

Desenvolvimento Sustentável (SVDS, 2016). 
Para realizar a pesquisa de campo, contudo, foi necessário calcular o espaço amostral, conforme Levin et al. (2012) determinam, para a aplicação dos questionários. Considerando que a população pesquisada é relativamente grande (em geral, maior do que 100 mil habitantes), de acordo com a estatística, aplicase a fórmula 1 :

$$
\mathbf{n}=\frac{\mathbf{Z}^{2} \cdot \mathbf{p} \cdot(1-\mathbf{p})}{\mathbf{e}^{2}}
$$

Em que: $\mathbf{n}$ é o tamanho da amostra a ser determinada; $\mathbf{Z}$ é uma variável padrão associada ao nível de confiança desejado; $\mathbf{p}$ é a probabilidade associada ao grau de homogeneidade da população; e e é o erro amostral admitido.

Esses parâmetros são definidos de acordo com as necessidades da pesquisa, a qual apresenta restrições de tempo e recursos para aplicação do questionário e análise dos resultados obtidos.

Foram adotados: $\mathbf{Z}=\mathbf{1}, \mathbf{6 5}$, correspondente a um grau de confiança da amostra de $90 \%$ em relação à universalidade da população; $\mathbf{p}=\mathbf{5 0 \%}$, valor padrão, utilizado em razão da inexistência de dados acerca da homogeneidade da população pesquisada; e $\mathbf{e}=\mathbf{1 0 \%}$, em função das limitações de tempo e recursos para aplicação dos questionários. Adotando tais valores, chegou-se à fórmula 2:

$$
\mathbf{n}=\frac{1,65^{2} \cdot 0,5 \cdot(1-0,5)}{0,1^{2}} \simeq 68
$$

Isso posto, para cada uma das populações a serem pesquisadas, estimou-se uma quantia de 68 questionários, ou seja, um total de 136 questionários, que foram aplicados e, posteriormente, analisados. Com esse recorte, buscou-se compor um quadro representativo da população como um todo e que, portanto, refletisse a realidade acerca das experiências relacionadas à crise hídrica que a população local de fato vivenciou. Ressalta-se ainda que o questionário aplicado consistiu em sete perguntas, as quais foram classificadas como perguntas fechadas de múltipla escolha, à exceção da última, que foi uma pergunta aberta:

- Você sentiu impactos da crise hídrica que atingiu Campinas a partir de 2012? Se sim, quais?

- Você adotou alguma medida ou mudou algum hábito durante o período da crise? Se sim, qual(is)?

- Você notou ações e/ou medidas da Prefeitura em seu bairro no período de seca? Se sim, quais?

- Na sua opinião, qual a origem da crise hídrica?

Por fim, terminada a pesquisa de campo, realizou-se a leitura dos resultados obtidos por meio dos questionários à luz do referencial teórico levantado: Acselrad et al. (2008), Alier (2007), Bullard (1983), Habermas (2013), Valêncio (2009), Villaça (2012), entre outros, que atribuem as diferenças socioeconômicas ao capital, que age de forma discricionária.

\section{Resultados e discussão}

Para melhor compreensão dos resultados coletados em campo, é interessante a apresentação prévia das duas sub-bacias deste estudo: do Ribeirão Anhumas e do Rio Capivari. Ressalta-se que o município enfrenta as consequências de um modelo de uso e ocupação do solo estabelecido décadas atrás, durante o processo de crescimento local, que resultou na presença de duas cidades distintas no mesmo território, uma pobre (com infraestrutura urbana ineficiente - como iluminação, redes de esgotamento, drenagem, 
pavimentação etc. -, ecossistemas degradados, equipamentos urbanos ausentes e vulnerabilidade social) e outra rica.

Um aspecto importante para a contextualização das sub-bacias estudadas é o exame de uso e ocupação do solo na região, já que, por meio de tal análise, pode-se observar as áreas mais carentes e mais dotadas de serviços e infraestruturas, denunciando, portanto, os locais de mais alta vulnerabilidade.

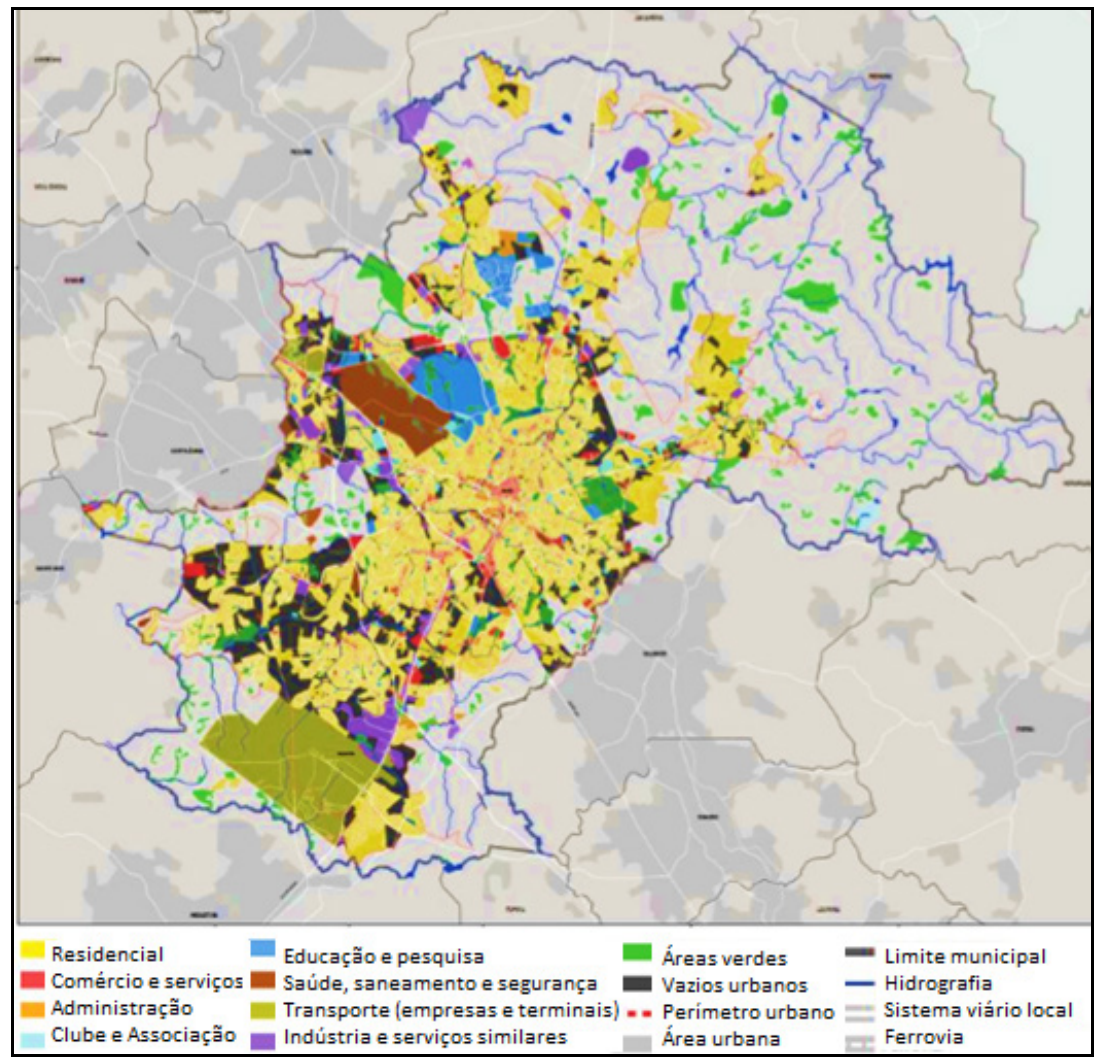

Figura 2 - Uso e ocupação do solo em Campinas. Fonte: Secretaria Municipal do Verde, do Meio Ambiente e do Desenvolvimento Sustentável (SVDS, 2016).

Por meio da análise da Figura 2, é possível observar o predomínio do uso residencial na porção central do município. Apesar de esse uso ser apresentado como homogêneo no mapa, destaca-se que nele estão enquadradas relevantes diferenças qualitativas habitacionais, ou seja, estão contempladas tanto habitações irregulares e informais sem acesso à infraestrutura quanto condomínios de alto padrão articulados à malha urbana. Nota-se também que as áreas verdes estão isoladas e fragmentadas, principalmente na região leste da cidade. As indústrias, conforme ilustra a Figura 2, concentram-se na porção sudoeste, assim como boa parte dos vazios urbanos. Já as instituições de educação e pesquisa, bem como as de saúde, saneamento e segurança, estão predominantemente nas áreas mais ao norte da cidade.

No que tange à bacia do Rio Capivari em específico, aproximadamente 200 mil habitantes residem nela, dos quais cerca de 50 mil moram em assentamentos precários, e mais de 60 mil, em conjuntos habitacionais produzidos pelo poder público (Sehab, 2011). Muitos loteamentos que se situam na região datam da década de 1950, quando ainda não era exigida dos loteadores a implantação de infraestrutura completa. As pessoas adquiriam esses lotes com a perspectiva de valorização futura, contudo muitos deles (em torno de 5 mil lotes) permanecem vazios até hoje, onerando a infraestrutura e os serviços urbanos locais (Sehab, 2011). Tem-se ainda que o uso do solo predominante na bacia é residencial, caracterizado por loteamentos populares, conjuntos habitacionais e ocupações ilegais. Nela, quase inexistem atividades econômicas e de lazer, o que denota que a área possui aspectos típicos de "regiõesdormitório". Para atividades básicas, como trabalho, lazer, compras etc., a população local é obrigada a 
constantes movimentos pendulares em direção ao centro urbano, o que é agravado pelas vias de acesso já saturadas ou em processo de saturação.

Em contrapartida, observou-se na bacia do Ribeirão Anhumas o predomínio de usos públicos e comerciais, o que pode ser explicado pela sua localização central e por seu histórico de ocupação. Em função disso, a população que nela habita tem à sua disposição uma considerável rede de infraestrutura e serviços. De acordo com Torres et al. (2014), as áreas de expansão urbana dessa bacia são pequenas, com um marcado predomínio de áreas residenciais de alta densidade (23\% da área urbanizada). Os usos urbanos recobrem $49 \%$ da área da bacia, enquanto os rurais, 37\%, e as áreas de vegetação, 13\%. Além disso, o movimento de expansão da mancha urbana da bacia incorporou um elevado grau de especulação imobiliária e de diferenciação de acesso ao espaço urbano para habitação local. Como resultado, aqueles que não puderam pagar ou resistir à valorização se viram forçados a migrar para bairros distantes (Torres et al., 2014).

Nesse contexto, destaca-se a questão da vulnerabilidade a que parte da população está sujeita. 0 Índice Paulista de Vulnerabilidade Social (IPVS) (SEADE, 2013) consiste em uma tipologia de situações de exposição à vulnerabilidade no espaço intraurbano, cujas variáveis componentes são de ordem socioeconômica e demográfica. Segundo esse índice, 15,4\% da população de Campinas se encontra em situação de baixíssima vulnerabilidade, e 44,7\%, em situação de vulnerabilidade muito baixa (SEADE, 2013). Esses grupos possuem o maior poder aquisitivo observado no município e habitam, principalmente, regiões, como Cambuí, Barão Geraldo, Sousas e Joaquim Egídio, localizadas predominantemente nas bacias Anhumas e Atibaia. No que concerne aos grupos de alta e muito alta vulnerabilidade, que representam, respectivamente, $5,4 \%$ e 7,8\% da população, estes se concentram nas bacias do Rio Capivari e Capivari-Mirim, regiões que abrigam muitas ocupações irregulares e novos empreendimentos, como previamente citado.

Aqui, recupera-se o conceito de justiça ambiental, cuja importância decorre da constatação de que a crescente escassez de recursos naturais e a desestabilização dos ecossistemas afetam, de modo desigual e injusto, diferentes grupos sociais. Por meio do estudo a respeito das sub-bacias do Ribeirão Anhumas e do Rio Capivari, torna-se evidente que as diferentes formas de degradação ambiental acontecem, predominantemente, onde vivem as populações de menor renda. Portanto, nota-se que o relacionamento entre sociedade e natureza reflete assimetrias políticas, sociais e econômicas fundamentais (Acselrad et al., 2008).

Em função das inúmeras discrepâncias socioambientais observadas entre as duas bacias investigadas, no início desta pesquisa formulou-se a hipótese de que haveria diferenças consideráveis entre as impressões e as vivências, relativas ao evento da crise hídrica no município de Campinas, das duas populações escolhidas, o que de fato se concretizou, já que houve uma diferença razoável entre o número de pessoas que sentiram impactos da crise hídrica em seu cotidiano: se na bacia do Rio Capivari a grande maioria (91\%) dos entrevistados afirmou ter sofrido consequências do período de estiagem de acordo com a Figura 3, na bacia do Ribeirão Anhumas esse número cai para 72\%, conforme a Figura 4.

\section{Sentiu impactos da crise hídrica? Pop. Rio Capivari}

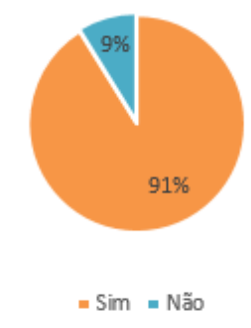

Figura 3 - População do Rio Capivari que sentiu impacto da crise hídrica. Fonte: elaborado pelas autoras (2017). 
Sentiu impactos da crise hídrica?

Pop. Ribeirão Anhumas

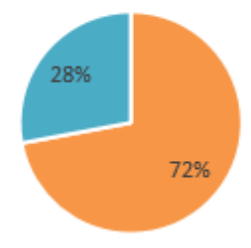

- Sim " Não

Figura 4 - População do Ribeirão Anhumas que sentiu impacto da crise hídrica. Fonte: elaborado pelas autoras (2017).

Quando questionados sobre os tipos de impacto que vivenciaram, a principal resposta entre os moradores da bacia do Rio Capivari foi o racionamento, citado por 49 dos 68 entrevistados. Na sequência, apareceram o aumento da conta (35) e os cortes d'água (19). Nesta pesquisa, entende-se por "racionamento" períodos do dia em que era realizado o corte d'água em determinados bairros do município, prática que poderia se repetir algumas vezes durante a semana. Aqui, vale ressaltar que Campinas ficou sob risco de racionamento em 77 ocasiões durante o ano de 2014 devido à baixa vazão do Rio Atibaia. Segundo o diretor da SANASA, Arly de Lara Romêo, apesar de a água usada no abastecimento da região ser captada diretamente do Rio Atibaia, este recebe água do Sistema Cantareira, que disponibiliza $31 \mathrm{~m}^{3} / \mathrm{s}$ de água à Região Metropolitana de São Paulo e $5 \mathrm{~m}^{3} / \mathrm{s}$ à bacia PCJ, em condições

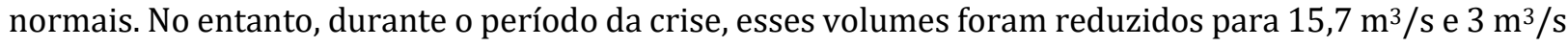
de água, respectivamente (Cruz, 2014), o que caracterizou a necessidade dos racionamentos.

Em contrapartida, conforme a Figura 5, a principal resposta dada pelos moradores do Ribeirão Anhumas foi o aumento da conta de água, citada por 38 pessoas, seguido do racionamento (28) e dos cortes d'água (24). Observa-se ainda que 12 moradores do Rio Capivari afirmaram ter recebido multas no período da seca, enquanto, na bacia do Ribeirão Anhumas, apenas uma pessoa disse ter passado por situação semelhante.

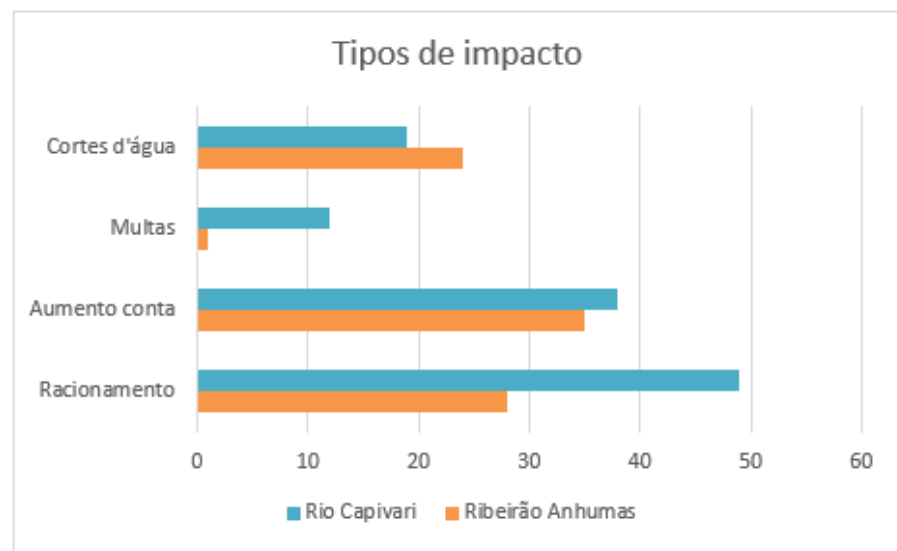

Figura 5 - Tipos de impacto sentidos pelos moradores entrevistados. Fonte: elaborado pelas autoras (2017).

No que diz respeito ao número de pessoas que mudaram algum hábito para economizar água, bem como às iniciativas tomadas para tal, os resultados coletados com as duas populações são bastante semelhantes: em ambas as bacias mais de $80 \%$ da população afirmou ter adotado alguma medida, sendo a economia de água no uso diário a mais citada. Na sequência, as medidas mais lembradas pelos moradores foram a reutilização de água e, por fim, com um número mínimo, novas formas de captação. 
Com relação às ações desenvolvidas pela Prefeitura no período da crise, as respostas das duas populações também foram semelhantes: apenas 33\% dos entrevistados na bacia do Ribeirão Anhumas e $29 \%$ da bacia do Rio Capivari afirmaram ter notado algum tipo de ação do poder público no sentido de reduzir os impactos da seca. Contudo, aqueles que disseram ter visto algum tipo de ação citaram, principalmente, a divulgação de campanhas de conscientização quanto ao consumo racional da água. Das 68 pessoas entrevistadas no Ribeirão Anhumas, quatro afirmaram que a Prefeitura realizou atividades para a promoção da educação ambiental e três disseram ter notado obras para melhoria da infraestrutura local. Na bacia do Rio Capivari, por outro lado, não se notou qualquer ação de educação ambiental, e apenas duas pessoas afirmaram que a Prefeitura realizou obras de melhoria na infraestrutura de seus respectivos bairros.

Por fim, quando questionados quanto à origem da crise hídrica, as respostas citadas foram as mais diversas. Observou-se o predomínio do motivo "problemas de gestão/planejamento" em ambas as bacias, seguido de "hábitos da população". Os moradores da bacia do Rio Capivari atribuíram também a falta de chuvas a um fenômeno climático inesperado. Muitos dos entrevistados ainda lembraram da "falta de infraestrutura municipal" como causa para a seca sentida. Citou-se o descontentamento com faltas de reservatórios d'água e adutoras insuficientes e/ou em mau estado de conservação. E, por fim, um grupo reduzido de pessoas (nove do Ribeirão Anhumas e cinco do Rio Capivari) citou a influência do desmatamento e da poluição na crise hídrica vivenciada. A Figura 6 ilustra tais resultados.

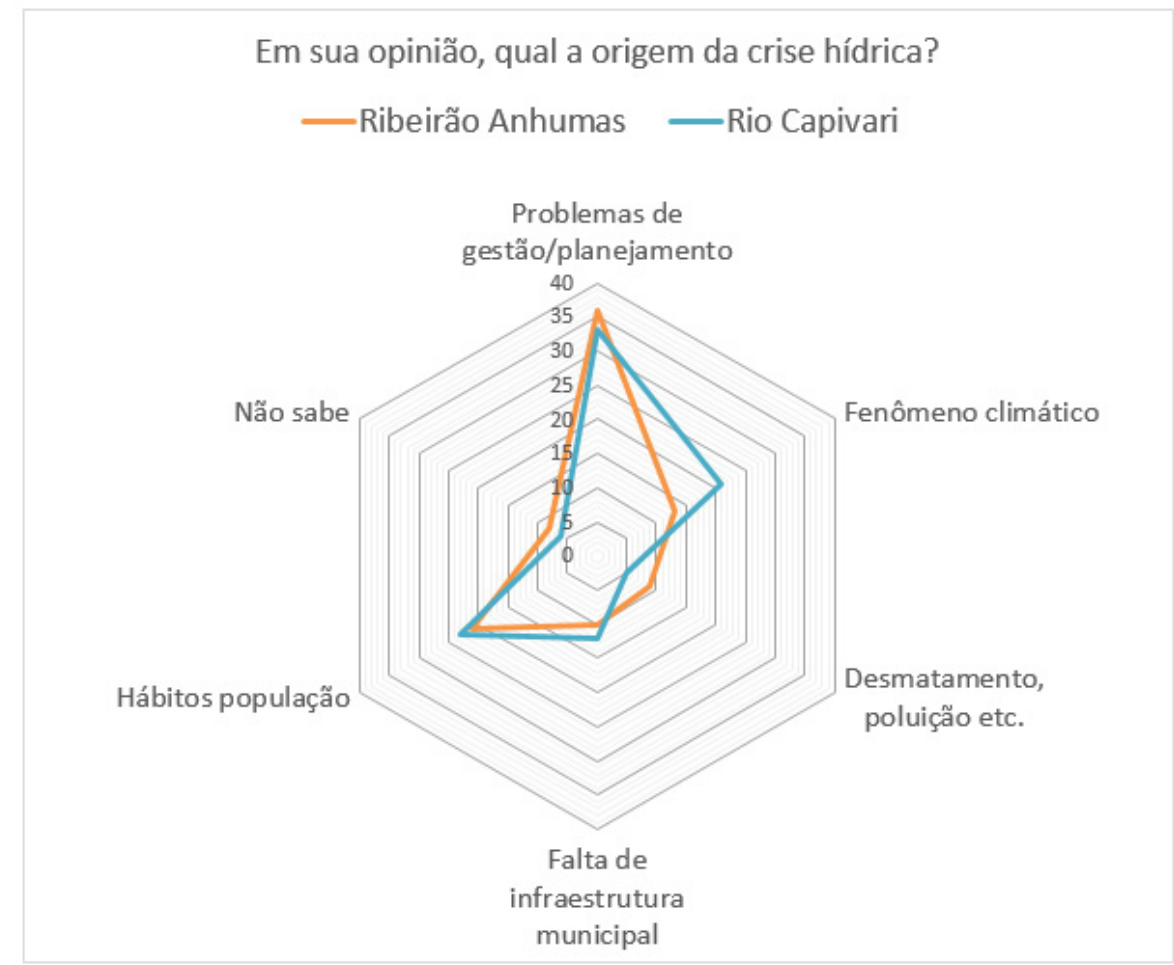

Figura 6. Opinião dos entrevistados quanto à origem da crise hídrica. Fonte: elaborado pelas autoras (2017).

Expostos os resultados coletados por meio da pesquisa de campo com a população das duas bacias, é possível tirar algumas conclusões. A primeira delas é que se pôde observar localmente os efeitos da injustiça ambiental. Diversos autores constatam que a maior parte dos riscos ambientais socialmente induzidos recai sobre os mais pobres e os grupos desprovidos de poder (como negros, indígenas, comunidades tradicionais, mulheres, crianças, idosos) (Acselrad et al., 2008; Alier, 2007; Bullard, 1983; Herculano, 2008; Valêncio, 2009), pois existe uma coincidência entre áreas de degradação ambiental e local de moradia de populações pobres em diversos países, o que rompe com a lógica simplista que defende a "democraticidade" dos riscos ambientais. 
Por meio do cruzamento de dados das dinâmicas de uso e ocupação, vulnerabilidade etc., com os relatos coletados em campo, conclui-se que não é coincidência que a maioria absoluta (91\%) dos entrevistados da bacia do Rio Capivari sentiu os efeitos da crise hídrica, enquanto, na bacia do Ribeirão Anhumas, a porcentagem de pessoas que sentiram os mesmos impactos seja consideravelmente mais baixa (72\%). A lógica capitalista segundo a que se está submetido segrega e exclui parte da população, a qual, por estar consequentemente mais alienada de seus direitos (Villaça, 2012), arca com os ônus de crises ambientais como a recentemente vivenciada.

Quando se analisam as principais consequências sentidas pela população no período de estiagem, os resultados se mostram como mais um fato revelador de uma realidade injusta: $72 \%$ da população do Rio Capivari sofreu com racionamento d'água, enquanto apenas $40 \%$ da população do Ribeirão Anhumas relatou a mesma situação. Ou seja, esse resultado da pesquisa parece indicar certa preferência, por parte da SANASA, em abastecer as áreas centrais do município, localizadas predominantemente na bacia do Ribeirão Anhumas.

Aqui, cabe chamar atenção para um evento que ocorreu em maio de 2014, na Câmara Municipal de Campinas, quando a SANASA apresentou um plano de racionamento para a crise hídrica, o qual deveria ser implementado caso fosse constatada a necessidade (SANASA, 2014). Meses mais tarde, em meados de 2016, como o documento não estava disponível no site da SANASA, solicitou-se o seu acesso com base na Lei de Acesso à Informação (Lei no 12.527/11). Em resposta à solicitação, a SANASA enviou um e-mail negando o pedido com base na justificativa de que o documento requerido seria de cunho estratégico e operacional da empresa e, portanto, estaria suscetível de ser "restringido a qualquer pessoa que não integre os cargos estratégicos da empresa", mesmo que o plano tivesse sido apresentado publicamente na Câmara Municipal meses antes. 0 e-mail, na íntegra, encontra-se transcrito em Silva (2017).

Foi feita mais uma tentativa: agendar uma entrevista com um técnico da SANASA, de modo a esclarecer alguns aspectos relativos à operacionalização das medidas de gestão da crise hídrica. Contudo, a empresa informou que a questão da crise hídrica deveria ser tratada exclusivamente pela assessoria de imprensa da SANASA, fato por si só controverso, já que a gestão da crise hídrica é de responsabilidade da comunidade, e não exclusivamente da referida empresa, a qual não deveria ter direitos exclusivos sobre a água, bem como das informações relativas a esse recurso. De todo modo, foram encaminhadas para a assessoria da SANASA as questões a serem esclarecidas, como aspectos relativos às medidas de combate à crise hídrica adotadas pela empresa, as áreas prioritárias para abastecimento etc. Contudo, apesar de as questões terem sido respondidas por um técnico da empresa, a divulgação desse conteúdo foi vetada. Indagado sobre o motivo desse veto, o funcionário, em conversa ao telefone, respondeu simplesmente que não era obrigação da SANASA repassar esse tipo de informação, ainda que a empresa seja uma prestadora de serviços públicos que tem como finalidade planejar, executar e operar serviços públicos de abastecimento de água e coleta de esgotos sanitários no município de Campinas.

Apesar do ocorrido, tais informações deveriam estar disponíveis nos meios idôneos de comunicação, tais como o site da empresa, conforme prevê a Lei de Acesso à Informação (Lei no 12.527/11). Considerando ainda que a SANASA é uma prestadora de serviços públicos, ela deveria zelar pela transparência de seus atos de administração pública, de modo a permitir o controle social previsto pelo inciso $\mathrm{V}$ do artigo $3^{\circ}$ da referida lei.

Já que, ao ser contatada, a SANASA evitou permitir entrevistas com seus técnicos ou divulgar informações, deixando a questão da crise hídrica no município ser tratada exclusivamente por sua assessoria de imprensa, buscou-se por maiores informações em outras fontes. Na Prefeitura de Campinas, conversou-se com um engenheiro ambiental da Secretaria Municipal do Verde a respeito da escolha das áreas que sofreram racionamento durante o período de seca. 0 entrevistado informou o seguinte:

o que sei é o que saiu na mídia. Me lembro de ter ouvido várias vezes o questionamento de porquê as áreas centrais estavam sendo priorizadas para abastecimento. Na época, além da prioridade de abastecimento de hospitais, escolas etc., discutiu-se a questão das redes. Nas áreas centrais as redes são mais antigas, então tem a questão da pressão. Se eles cortassem ou reduzissem a pressão, corria o risco de danificar a tubulação. Então estas eram as duas principais justificativas relacionadas ao 
plano de racionamento da SANASA. Mas também não tive acesso ao Plano de Racionamento. O que me lembro da época foi o que foi publicado nos principais meios de comunicação (Geraldo Ribeiro de Andrade Neto).

Esse episódio, somado às impressões dos moradores em relação às ações do poder público no sentido de reduzir os efeitos de crise, indica o descaso com a população em geral e, em especial, com a população periférica, que parece ter arcado com as maiores consequências da crise hídrica no município. Além disso, evidencia-se a preocupante falta de transparência da SANASA no que tange aos aspectos relacionados à gestão dos recursos hídricos municipais. Nesse contexto, foram explorados, na sequência, alguns dos mecanismos que regem essa lógica de injustiça ambiental percebida localmente, mas que se manifesta em todo o mundo.

\section{Mecanismos da injustiça ambiental}

Atualmente, diversos meios de disseminação de ideias e valores apontam que a degradação ambiental, fruto das mudanças climáticas globais, da exploração antrópica dos recursos naturais e da aplicação de técnicas nocivas ao meio ambiente, é um dos grandes males da sociedade contemporânea, cujas consequências podem afetar a todos indistintamente (Acselrad et al., 2008). De acordo com tal lógica, os riscos inerentes a essas práticas poluidoras e destrutivas desenvolvidas no planeta fariam com que todos fossem vítimas em potencial, já que habitam no mesmo macroecossistema, o planeta Terra. Esse pensamento se constitui, contudo, em uma falácia.

Torres \& Marques (2001) desenvolveram um estudo no qual foram sobrepostas as áreas de risco às diversas formas de desigualdade social e residencial. Com isso, foi possível verificar que a renda constitui uma variável central no que diz respeito à distribuição da desproteção ambiental, dinâmica que leva a diversos desastres observados em todo o Brasil, os quais estão relacionadas ao mercado de terras. Logo, essa dinâmica faz com que as famílias de baixa renda se instalem em áreas ignoradas pelo mercado imobiliário formal, nas quais, geralmente, já existem riscos ambientais.

A desigualdade ambiental proveniente dessa dinâmica capitalista gera diversas consequências que podem se manifestar por meio da proteção ambiental desigual e do acesso desproporcional aos recursos ambientais. Diz-se que há proteção ambiental desigual quando as políticas ambientais geram riscos desproporcionais para as populações mais carentes de recursos financeiros e políticos. Tal diferença no grau de exposição aos riscos provém de procedimentos sociopolíticos que distribuem de forma desigual os riscos ambientais. Estes, por sua vez, frequentemente ocorrem por intermédio de processos privados de decisão, caracterizados, portanto, como não democráticos. Como consequência, observa-se que a elaboração e a aplicação de políticas sob a forma de normas discriminatórias e de prioridades não discutidas frequentemente produzem efeitos desproporcionais sobre diferentes grupos sociais (Acselrad et al., 2008). Trata-se exatamente do que foi observado em Campinas, onde não houve diálogo dos órgãos competentes com os moradores das áreas que sofreram racionamento, e os moradores das regiões periféricas sentiram mais intensamente os impactos da seca.

0 autor ainda defende que a pobreza generalizada enfrentada por diversos países é produto de processos sociais de despossessão, de disciplinamento e de exploração para a produção de bens e riquezas que são apropriados pelos mais ricos. Esses processos são os motores de produção da desigualdade social - raiz da degradação ambiental - e da pobreza. Logo, não se pode combater a crise ambiental sem promover justiça ambiental. Para isso, contudo, são imprescindíveis a transparência dos órgãos gestores e a participação da população.

No que diz respeito ao município de Campinas, a falta de transparência observada por parte da SANASA, no que tange aos aspectos de gestão dos recursos hídricos municipais e de prestação de contas pública, pareceu impedir a plena participação da população, o que pode ser encarado como um alerta para a necessidade de pressão e participação popular quanto às ações de gestão pública locais, já que esse é um direito previsto pela legislação. Nesse sentido, um dos princípios do direito ambiental, o princípio 
democrático, encontra sua expressão normativa nos direitos à informação e à participação, os quais estão expressamente previstos na Constituição e em leis esparsas. 0 direito ambiental, em seus aspectos regulatórios, depende da administração pública, a qual tem no princípio da publicidade administrativa um dos seus alicerces (Antunes, 2017). Ou seja, todo ato administrativo deve ter ampla publicidade ao longo do processo, de modo a garantir a transparência e a accountability - conceito que denota a necessidade de prestação de contas do gestor público, bem como sua responsabilidade legal. Ainda de acordo com o autor:

“O princípio democrático assegura aos cidadãos o direito de, na forma da lei ou regulamento, participar das discussões para a elaboração das políticas públicas ambientais e de obter informações dos órgãos públicos sobre matéria referente à defesa do meio ambiente e de empreendimentos utilizadores de recursos ambientais e que tenham significativas repercussões sobre o ambiente, resguardado o sigilo industrial." (Antunes, 2017, p. 21).

\section{Transparência e participação}

Apesar do cenário pessimista global de injustiça ambiental e local relacionado à falta d'água vivenciada no município de Campinas, a pesquisa de campo realizada apontou que a população do município parece estar ciente de que o evento de seca, que acometeu o Sudeste brasileiro entre $2012 \mathrm{e}$ 2014, tem suas origens no gerenciamento inadequado das águas e na falta de investimentos em infraestruturas de captação e distribuição, o que reside nas ações e nas estratégias insatisfatórias dos órgãos competentes. Logo, é necessário que os agentes públicos relacionados à gestão dos recursos hídricos sejam mais cobrados a prestar contas à população.

Interessante analisar também a atribuição da falta de água aos maus hábitos da população, como muitos dos entrevistados citaram. Ressalta-se, contudo, que não há como culpar a população pelo mau uso da água, pois ela nunca foi bem informada e preparada para tal. A realização de medidas de caráter conscientizador apenas no período de crise não é suficiente para criar uma verdadeira percepção pública quanto à necessidade de utilizar racionalmente a água. Mais do que isso, terminado o período crítico de seca e suspensas as propagandas de consumo consciente, a tendência é que a população retome seus antigos hábitos. Inclusive, destaca-se que, durante o final da crise hídrica, propagandas da Prefeitura Municipal incentivavam a população a consumir mais água, dando "bandeira verde" para a utilização de água (Prefeitura Municipal de Campinas, 2015). Nesse sentido, a educação ambiental - efetiva, crítica e constante - aparece como necessária para evitar crises como a enfrentada. Porém, conforme a pesquisa de campo revela, as medidas municipais de educação ambiental foram mínimas.

Observando os usos da água na bacia PCJ, levantados por Bueno \& Pera (2014) e constantes na Tabela 1, conclui-se que, apesar de a utilização dos recursos hídricos para abastecimento público corresponder a aproximadamente $50 \%$ do total de água utilizada, a indústria e a agricultura representam os outros $50 \%$ e, portanto, devem ser trazidas à discussão e pressionadas para que façam sua parte na economia, reaproveitamento e uso consciente da água.

Tabela 1 - Uso da água nas Unidades de Gerenciamento de Recursos Hídricos (UGRHIs) n 5, 6 e 7

\begin{tabular}{|c|c|c|c|c|c|}
\hline & $\begin{array}{l}\text { Demanda } \\
\text { total }\left(\mathrm{m}^{3} / \mathrm{s}\right)\end{array}$ & $\begin{array}{c}\text { Abastecimento } \\
\text { público (\%) }\end{array}$ & $\begin{array}{l}\text { Uso } \\
\text { industrial } \\
\text { (\%) }\end{array}$ & $\begin{array}{l}\text { Irrigação } \\
\text { agrícola (\%) }\end{array}$ & $\begin{array}{l}\text { Outros } \\
(\%)\end{array}$ \\
\hline $\begin{array}{c}\text { 1. Outorgas de captação da Bacia do Alto } \\
\text { Tietê }\end{array}$ & 59,2 & 58 & 39 & 1 & 2 \\
\hline $\begin{array}{l}\text { 2. Demanda de água superficial e } \\
\text { subterrânea da Bacia da Baixada Santista }\end{array}$ & 23,9 & $\begin{array}{l}\text { Uso doméstico } \\
\qquad 45,3\end{array}$ & 52,1 & 0 & 2,6 \\
\hline $\begin{array}{l}\text { 3. Demanda das Bacias Piracicaba, Capivari } \\
\text { e Jaguari (não incluído uso urbano da Grande } \\
\text { São Paulo de } 31 \mathrm{~m}^{3} / \mathrm{s} \text { a } 24 \mathrm{~m}^{3} / \mathrm{s} \text { referente ao } \\
\text { Sistema Cantareira, conforme outorga) }\end{array}$ & 36,3 & $\begin{array}{c}\text { Demanda urbana } \\
52,4\end{array}$ & 29,2 & 18,4 & 0 \\
\hline
\end{tabular}

Fonte: Bueno \& Pera (2014). 
Infere-se, portanto, que a principal atividade da municipalidade no sentido reduzir os efeitos da crise hídrica (a conscientização sobre o uso racional da água por meio de propagandas) pode ter influenciado na percepção dos moradores quanto à origem da seca. Parece não ter havido transparência a todos os atores envolvidos e, em parte, responsáveis pela falta de água na região. 0 diálogo, a transparência das ações e das informações e a chamada "corresponsabilização" se tornam, portanto, imprescindíveis no combate ao desperdício e a crises como a vivenciada, já que tanto o poder público quanto a população são responsáveis pela gestão ambiental municipal (Castro, 2015).

Nesse sentido, no Brasil, destaca-se a falta de aproximação entre as decisões políticas de caráter ambiental e a efetiva participação popular. Quando se busca um enfoque participativo, deve-se analisar não o que se chama normalmente de instrumento, métodos ou técnicas, mas sim aquilo se constitui na questão central da participação: as disputas sobre e pelo poder (Santos \& Saito, 2006). Ou seja, é insuficiente haver participação social quando, na verdade, o poder não é distribuído e repensado (Brose, 2001).

De acordo com Santos \& Saito (2006), a participação é vista como o conjunto de ações que servem muito mais para justificar as estruturas organizacionais e legitimar a situação atual do que questioná-la ou mudá-la para melhor. Uma comprovação disso são as ações locais, públicas e privadas, adaptadas a cada novo projeto implementado, desde que não afete o poder das oligarquias locais. Os autores destacam ainda que, apesar da exaltação da defesa do princípio participativo previsto na Política Nacional de Recursos Hídricos, cabe destacar que a discussão sobre participação aparece de forma mitificada, já que é apresentada como se o simples fato de estar em lei seria suficiente para uma real participação.

Muitos dos entrevistados demonstraram desconfiança em relação aos órgãos gestores da crise, como a SANASA, e às técnicas por eles aplicadas, apontando-os como principais responsáveis pelo gerenciamento inadequado da crise hídrica vivenciada no período analisado. Tal desconfiança da "técnica" provém da falta de transparência, aliada à falta de seu domínio. Nesse contexto, os cidadãos se limitam a criticá-la e a exigir prestação de contas, situação que é agravada pela falta de informações disponíveis a respeito das atividades desenvolvidas pela SANASA, o que impede que a população exerça o controle social que lhe é de direito.

Ressalta-se, por fim, o fundamental papel das universidades no gerenciamento de crises hídricas como a de 2014. Considerando o papel da universidade - de produzir conhecimento, gerar pensamento crítico, articular saberes e formar profissionais -, é bastante latente a necessidade de aproximação dela com o restante da sociedade, para que os acadêmicos produtores de conhecimento dialoguem com problemas reais do cotidiano e do mercado para oferecer soluções viáveis.

Do exposto, fica clara a necessidade de se repensar o manejo e a gestão das águas em diversas escalas. No Brasil, como em diversos outros países, a questão ambiental mobiliza apenas enquanto se caracteriza como um problema agudo. Dessa forma, é essencial naturalizar a discussão para que ela se torne parte do cotidiano das pessoas, de modo a desenvolver uma verdadeira consciência ambiental. Com isso, há esperança de que a crise ambiental-urbana enfrentada hoje possa ser revertida porque será prevenida a todo momento, e não apenas em cenários de crise como o aqui descrito.

\section{Conclusões}

O estudo de caso ora relatado demonstra a indissociabilidade das questões ambiental e social, já que os processos político-econômicos que se desenvolvem nos centros urbanos afetam, além dos ecossistemas naturais, as populações desprovidas de poder de renda, que acabam arcando com a maior parte do ônus do chamado desenvolvimento. Dessa maneira, a gestão dos recursos hídricos no município de Campinas afetou, de modo desigual e injusto, as diferentes populações estudadas, o que constitui um exemplo da atuação das forças políticas envolvidas e das consequências desse modelo econômico infligidas às comunidades mais vulneráveis.

Outro ponto a ser destacado se relaciona à contradição existente entre os diversos dispositivos legais que visam à proteção do meio ambiente e o precário cenário ambiental que marca o Brasil atual. Apesar 
de todos os avanços legais das últimas décadas, ainda há questões socioambientais basais que precisam ser resolvidas. A dificuldade de implementação de uma gestão integrada de recursos hídricos se destaca e merece especial atenção para que possa ser de fato colocada em prática. Desse modo, os espaços de participação cidadã são de extrema importância, pois favorecem a representação de interesses diversos e instigam à resposta pública de demandas sociais e as legitimam. Nesse sentido, destaca-se a descrença da população em relação à SANASA. Portanto, a educação socioambiental, pressuposto para uma participação efetiva e consciente, tem papel central nessa discussão.

Destaca-se, por fim, que a atual crise ambiental vivenciada possui caráter multifacetado, e não somente ambiental (Wallerstein, 2003). 0 caminho para uma sociedade mais sustentável e justa se fortalece no desenvolvimento de práticas pautadas pelo paradigma da complexidade que levem às esferas sociopolíticas uma atitude reflexiva em torno da problemática ambiental, bem como aos efeitos gerados por uma sociedade cada vez mais utilitarista, visando traduzir o conceito de ambiente e o pensamento da complexidade na formação de novas mentalidades, conhecimentos e comportamentos (Jacobi et al., 2015). Isso posto, o combate a tais conflitos socioambientais é fundamental para reduzir não só a vulnerabilidade das populações atingidas, mas também promover a cidadania e a dignidade humana.

\section{Referências}

Acselrad, H., Mello, C., \& Bezerra, G. (2008). O que é justiça ambiental? Rio de Janeiro: Garamond.

Alier, J. (2007). O ecologismo dos pobres (2a ed.). São Paulo: Contexto.

Antunes, P. B. (2017). Direito Ambiental. (19a ed.). São Paulo: Atlas.

Brose, M. (Org). (2001). Metodologia Participativa. Porto Alegre: Tomo.

Bueno, L., \& Pera, C. (2014). Crise da Água nas Metrópoles? Ocupação dispersa planejada pelos investimentos públicos, ganância privada e desgovernança regional. In Anais do III Encontro da Associação Nacional de Pesquisa e Pós-graduação em Arquitetura e Urbanismo. (pp. 1-17). São Paulo: ANPARQ.

Bullard, R. (1983). Confronting environmental racismo: Voices from the grassroots. Boston: South End Press.

Castro, G. (2015, novembro 9). Crise da água reflete também uma crise de informações, analisam especialistas. Jornal USP. Recuperado em 2 de outubro de 2017, de http://www5.usp.br/100662/crise-da-agua-reflete-tambemuma-crise-de-informacoes-analisam-especialistas /

Coriolano, G. P., Rogrigues, W., \& Oliveira, A. F. D. (2013). Estatuto da Cidade e seus instrumentos de combate às desigualdades socioterritoriais: o Plano Diretor Participativo de Palmas (TO). Urbe. Revista Brasileira de Gestão Urbana, 5(2), 131-145. http://dx.doi.org/10.7213/urbe.05.002.AC04.

Cruz, F. (2014, 04 de dezembro). Assessor da Sabesp atribui crise a um fenômeno imprevisível: Antônio César participou do seminário "Crise da escassez hídrica no Brasil e seu gerenciamento no estado de São Paulo". Revista Exame. Recuperado em 15 de outubro de 2017, de http://exame.abril.com.br/brasil/assessor-da-sabesp-atribuicrise-a-um-fenomeno-imprevisivel/

Fundação Sistema Estadual de Análise de Dados - SEADE. (2013). Índice Paulista de Vulnerabilidade Social - IPVS versão 2010. São Paulo: SEADE. Recuperado em 15 de agosto de 2017, de

http://www.iprs.seade.gov.br/ipvs2010/view/pdf/ipvs/metodologia.pdf

Habermas, J. (2013) Teoria e práxis: estudos de filosofia social. São Paulo: Editora UNESP.

Herculano, S. (2008). O clamor por justiça ambiental e contra o racismo ambiental. Revista de Gestão Integrada em Saúde do Trabalho e do Meio Ambiente, 3(1), 1-20.

Instituto Brasileiro de Geografia e Estatística - IBGE. (2010). Censo demográfico: população residente 1872 - 2010. Rio de Janeiro: IBGE. Recuperado em 10 de outubro de 2018, de https://www.ibge.gov.br/estatisticasnovoportal/sociais/populacao/9662-censo-demografico-2010.html?=\&t=series-historicas

Intergovernmental Panel on Climate Change - IPCC. (2014). Climate Change 2014: Synthesis Report. Contribution of Working Groups I, II and III to the Fifth Assessment Report of the Intergovernmental Panel on Climate Change (p.

151) Geneva: IPCC. 
Jacobi, P. R., Cibim, J., \& Leão, R. S. (2015). Crise hídrica na Macrometrópole Paulista e respostas da sociedade civil. Revista Estudos Avançados, 29(84), 27-42. http://dx.doi.org/10.1590/S0103-40142015000200003.

Levin, J., Fox, J. A. \& Forde, D. R. (2012). Estatística para ciências humanas (11a ed.). São Paulo: Pearson Education do Brasil.

Marengo, J. A., Nobre, C. A., Seluchi, A. E., Cuartas, A., Alves, L. M., Mendiondo, E. M., Obregón, G. \& Sampaio, G. (2015). A seca e a crise hídrica de 2014 - 2015 em São Paulo. Revista USP, 106, 31-44.

Prefeitura Municipal de Campinas (2015). Campanha informa a situação do abastecimento no município de Campinas. Recuperado em 27 de outubro de 2016, de http://www.campinas.sp.gov.br/noticiasintegra.php?id=27474

Programa das Nações Unidas para o Desenvolvimento - PNUD, Instituto de Pesquisa Econômica Aplicada - IPEA Fundação João Pinheiro - FJP. (2015). Atlas do Desenvolvimento Humano nas Regiões Metropolitanas Brasileiras: Baixada Santista, Campinas, Maceió e Vale do Paraíba (67 p.) Brasília: PNUD, IPEA e FJP.

Reis, T. (2014). Início de 2014 em São Paulo é o mais quente da série histórica do Inmet. Jornal G1. Recuperado em 17 de outubro de 2018, de http://g1.globo.com/sao-paulo/noticia/2014/01/inicio-de-2014-em-sao-paulo-e-omais-quente-da-serie-historica-do-inmet.html

Santos, I., \& Saito, C. (2006). A mitificação da participação social na política nacional de recursos hídricos - gênese, motivação e inclusão social. Geosul, 21(42), 7-27.

Santos, M. (2005). A urbanização brasileira (5th ed.). São Paulo: Editora da Universidade de São Paulo.

Secretaria Municipal de Habitação - Sehab. (2011). Plano Municipal Habitação de Campinas. Campinas: Sehab.

Secretaria Municipal do Verde, do Meio Ambiente e do Desenvolvimento Sustentável - SVDS. (2016). Plano Municipal de Recursos Hídricos - Volume I: Panorama e estado dos recursos hídricos. (2a Ed.). Campinas: SVDS.

Silva, J. L. (2017). Crônica de uma seca anunciada: A crise hídrica em Campinas - SP e seus impactos sobre as populações das bacias hidrográficas do Ribeirão Anhumas e do Rio Capivari (2012 - 2016) (Dissertação de mestrado). Centro de Ciências Exatas, Ambientais e de Tecnologias, PUC-Campinas, Campinas.

Sociedade de Abastecimento de Água e Saneamento S/A - SANASA. (2014). SANASA apresenta na Câmara Municipal plano para a crise hídrica. Recuperado em 28 de maio de 2014, de

<http://www.sanasa.com.br/conteudo/conteudo2.aspx?par_nrod=1831\&flag=P-A>

Torres, R.B., Adami, S. F. \& Coelho, R.M. (Org.). (2014). Atlas socioambiental da bacia do ribeirão das Anhumas. Campinas: Pontes Editores.

Torres, H., \& Marques, E. (2001). Reflexões sobre a hiperperiferia: novas e velhas faces da pobreza no entorno metropolitano. Revista Brasileira de Estudos Urbanos e Regionais, 40(4), 49-70. http://dx.doi.org/10.22296/23171529.2001n4p49.

Tundisi, J. G. (2008). Recursos hídricos no futuro: problemas e soluções. Revista Estudos Avançados, 22(63), 7-16. http://dx.doi.org/10.1590/S0103-40142008000200002.

Valêncio, N. (2009). Da 'área de risco' ao abrigo temporário: uma análise dos conflitos subjacentes a uma territorialidade precária. In Valêncio, N. et al. (Org.), Sociologia dos Desastres: Construção, interfaces e perspectivas no Brasil. São Carlos: RiMa Editora.

Villaça, F. (2012). Reflexões sobre as cidades brasileiras. São Paulo: Studio Nobel.

Wallerstein, I. (2003). Mundialização ou Era de Transição? uma visão de longo prazo da trajetória do SistemaMundo. In F. Chesnais, G. Duménil, D. Lévy, I. Wallerstein. Uma Nova Fase do Capitalismo? São Paulo: Xamã.

Editor: Harry Bollmann

Submissão: 13 Nov. 2017

Aceite: 26 Nov. 2018 